\title{
Study features of quantitative characteristics of organic compounds sorption by metallurgical slag
}

\author{
Khobotova E., Hraivoronska I. ${ }^{*}$ \\ Kharkiv National Automobile and Highway University, Kharkiv, Ukraine
}

Received: $07.06 .2018 \quad$ Accepted: 05.09 .2018

\begin{abstract}
The adsorption of aromatic compounds on a slag sorbent was studied. The effect of the acidity of the solution on the adsorption of weak organic electrolytes is shown. The equations of adsorption are derived. The main types of interaction are determined: dispersion, electrostatic induction and orientational, intermolecular hydrogen bonding, ion pair formation. It is shown that low-molecular aromatic compounds are adsorbed in a nondissociated form. The mineralogical composition of metallurgical slag was researched. The possibility of the using of slags with the main diopside mineral as sorbents for the water purification has been shown. The slag sorption activity is caused by high content of diopside in the amorphous state. The possibility of slag sorption of the organic substances was shown. To increase the degree of loosening the surface, increasing the number of compounds in the amorphous state and increase of adsorption capacity of slag is necessary to conduct its chemical activation. Optimum conditions for chemical slag activation were defined. A presence is hydroxylic and silanolic groups on the surface of slags particles have been shown. The acid activating of slags that increases the amount of adsorption centers $\mathrm{OH}$ and Si$\mathrm{OH}$ have been recommended. The large degree of hydratation, hydroxylating and concentration of siloksan groups and groups of Al-O-Si on the surface metallurgical slag on the basis of diopside has been shown. The presence of admixture of aluminum in slags gives the surfaces of silicates properties of chemical sorption in relation to the molecules of donors of electrons.
\end{abstract}

Key words: slag; sorbent; adsorption; aromatic compounds; acidity; study features.

\section{Особливості вивчення кількісних характеристик сорбції органічних сполук металургійним шлаком}

\author{
Хоботова Е. Б., Грайворонська І. В. \\ Харківський національний автомобільно-дорожній університет, Харків, Україна
}

\begin{abstract}
Анотація. Вивчено адсорбцію ароматичних сполук на шлаковому сорбенті. Показано вплив кислотності розчину на адсорбцію слабких органічних електролітів. Виведено рівняння адсорбції. Визначено основні типи взаємодії: дисперсійне, електростатичне індукційне і орієнтаційне, міжмолекулярний водневий зв'язок, утворення іонних пар. Показано, що низькомолекулярні ароматичні сполуки адсорбуються в недисоційованій формі. Досліджено мінералогічний склад металургійного шлаку. Показана можливість використання шлаків 3 основним мінералом діопсидом в якості сорбентів для очистки води. Активність сорбції шлаку обумовлена високим вмістом діопсиду в аморфному стані. Показана можливість сорбції шлаку органічними речовинами. Щоб збільшити ступінь ослаблення поверхні, необхідно збільшити кількість з'єднань в аморфрному стані і збільшити адсорбційну здатність шлаку для його хімічної активації. Визначено оптимальні умови хімічної активації шлаку. Було показано наявність гідроксильних і силанольних груп на поверхні частинок шлаків. Було рекомендовано кислотне активування шлаків, яке збільшує кількість адсорбційних центрів OH i Si-OH. Показана велика ступінь гідратації, гідроксилювання і концентрації силоксанових груп і груп $\quad$ Al-O-Si на поверхні металургійного шлаку на основі діопсиду. Присутність домішок алюмінію в шлаках дає поверхні силікатів властивості хімічної сорбції по відношенню до молекул донорів електронів.
\end{abstract}

Ключові слова: шлак, сорбент; адсорбція; ароматичні сполуки; кислотність; особливості вивчення.

\footnotetext{
Corresponding Author: Hraivoronska Inna Valeriivna. Phone: (050)859-64-14. E-mail: inna_gra@ukr.net Kharkiv National Automobile and Highway University, vul. Yaroslava Mudroho, 25, Kharkiv, Ukraine, 61002.

Biдnовідальний автор: Грайворонська Інна Валеріївна. Тел. (050)859-64-14. E-mail: inna_gra@ukr.net Харківський національний автомобільно-дорожній університет, вул. Ярослава Мудрого, 25, м. Харків, Україна, 61002.
} 


\title{
Особенности изучения количественных характеристик сорбции органических соединений металлургическим шлаком
}

\author{
Хоботова Э. Б., Грайворонская И. В.
}

Харьковский национальный автомобильно-дорожный университет, Харьков, Украина

\begin{abstract}
Аннотация. Изучена адсорбция ароматических соединений на шлаковом сорбенте. Показано влияние кислотности раствора на адсорбцию слабых органических электролитов. Выведены уравнения адсорбции. Определены основные типы взаимодействия: дисперсионное, электростатическое индукционное и ориентационное, межмолекулярная водородная связь, образование ионных пар. Показано, что низкомолекулярные ароматические соединения адсорбируются в недиссоциированной форме. Исследован минералогический состав металлургического шлака. Показана возможность использования шлаков с основным минералом диопсидом в качестве сорбентов для очистки воды. Активность сорбции шлака обусловлена высоким содержанием диопсида в аморфном состоянии. Показана возможность сорбции шлака органическими веществами. Чтобы увеличить степень ослабления поверхности, необходимо увеличить количество соединений в аморфном состоянии и увеличить адсорбционную способность шлака для его химической активации. Определены оптимальные условия химической активации шлака. Было показано наличие гидроксильных и силанольных групп на поверхности частиц шлаков. Было рекомендовано кислотное активирование шлаков, которое увеличивает количество адсорбционных центров OH и Si-OH. Показана большая степень гидратации, гидроксилирования и концентрации силоксановых групп и групп Al-O-Si на поверхности металлургического шлака на основе диопсида. Присутствие примеси алюминия в шлаках дает поверхности силикатов свойства химической сорбции по отношению к молекулам доноров электронов.

Ключевые слова: шлак; сорбент; адсорбция; ароматические соединения; кислотность; особенности изучения.
\end{abstract}

\section{Bcmyn}

Постановка проблеми. Для оптимізації технологічних процесів очищення вод необхідно вивчення поєднання хімії поверхні шлакових адсорбентів і природи міжмолекулярних взаємодій з різними сорбатами. При створенні технологічних схем адсорбційної очистки вод треба мати відомості про адсорбційні можливості ряду органічних сполук на шлаках, їх відсутність ускладнює вибір оптимального режиму технологічного циклу «Адсорбція - десорбція».

Аналіз літератури. При вивченні адсорбції низькомолекулярних ароматичних сполук на шлаковому сорбенті як сорбати обрані найбільш поширені забруднювачі стічних вод підприємств ряду галузей промисловості: фенол, $n$-нітрофенол, анілін і $n$-нітроанілін. Однією з причин адсорбції плоских молекул ароматичних похідних бензолу на гідроксильованої поверхні кремнеземів $є$ водневі зв'язки пелектронів бензольного кільця з поверхневими силанольними групами [1].

Як шлаковий сорбент використовувався шлак Побузького феронікелевого комбінату (ПФНК) виробництва сплаву FeNi. Раніше [2-5] було показано, що основний мінерал шлаку - діопсид, а поверхневими функціональними групами шлакових частинок $€$ гідрофрільні силанольні $\mathrm{Si}-\mathrm{OH}$ i силоксанові Si-O-Si групи.

Причому, частка силанольних груп зростає при збільшенні ступеня гідроксилювання поверхні характерного для кислотної активації шлаку. Згідно з літературними даними [6] концентрація поверхневих силанольних груп на гідроксильованої поверхні кремнезему невисока і складає $5 \mathrm{OH}-$ груп/нм².

Невирішені питання. Залишаються неповністю вирішеними питання сорбційної очистки промислових стічних вод від органічних сполук при використанні металургійних шлаків як сорбентів шляхом об'єднання екологічних аспектів зменшення кількості стоків та утилізації шлаків.

Mema роботи - підвищення ефективності вивчення особливостей визначення кінетичних характеристик адсорбції ароматичних сполук шлаковим сорбентом та визначення кількісного опису процесу адсорбції з виявленням основних типів взаємодій. 


\section{II Матеріал і методи дослідження}

Адсорбцію проводили в статичному режимі протягом 3 діб. Концентрації сполук в розчині визначали методом газової хроматографії.

Кількісні кінетичні характеристики та типи взаємодій при адсорбції органічних сполук шлаком. Згідно з результатами адсорбції (див. табл. 1) ароматичні сполуки можна розташувати в ряд збільшення ефективності адсорбції:

$$
\text { n-нітрофренол <френол <анілін <n-нітроанілін. }
$$

Табл. 1. Ефективність адсорбційного вилучення ароматичних сполук шлаком ПФНК, що

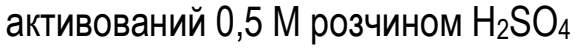

\begin{tabular}{|c|c|}
\hline $\begin{array}{c}\text { Розчини сполук концентрації } \\
0,01 \text { г/дм }^{3}\end{array}$ & Ефективність вилучення сорбатів, \% \\
\hline$n$-нітрофенол & 26,0 \\
\hline фенол & 32,7 \\
\hline анілін & 42,9 \\
\hline$n$-нітроанілін & 94,5 \\
\hline
\end{tabular}

Різна адсорбція молекул ароматичних сполук може визначатися низкою факторів, пов'язаних з їх хімічною природою, серед яких величина постійного дипольного моменту, ймовірність утворення водневого зв'язку ароматичних молекул з молекулами води і ОН-групами гідроксильованої поверхні адсорбенту, здатність до дисоціації сполук як слабких електролітів та ін. Симетричне розташування гідрофільної і гідрофобної груп створює умови для фіксованої орієнтації молекул в адсорбційної фразі, що робить можливою щільну їх упаковку на поверхні шлакового сорбенту.

Велике значення для адсорбції ароматичних сполук має міжмолекулярний водневий зв'язок, що утворюється між фуннкціональними групами поверхні адсорбенту і ароматичних речовин. Енергія водневого зв'язку в 2-4 рази більше енергії дисперсійної взаємодії адсорбованих молекул з поверхнею. Найбільш ефективно в подібну міжмолекулярну взаємодію вступають групи -OH i - $\mathrm{NH}_{2}$.

Менш виражена адсорбція $n$-нітрофенолу в порівнянні 3 фенолом, ймовірно, пов'язана 3 відтягуванням електронної щільності з бензольного кільця молекули фенолу нітрогрупою в результаті чого негативний заряд на атомі кисню зменшується, що призводить до ослаблення водневого зв'язку між фенольною групою і ОН-групами поверхні шлаку. Для аніліну і $n$-нітроаніліну аналогічний ефект не спостерігається.

\section{III Результати}

Визначено зменшення концентрації аніліну в розчині в часі при протіканні адсорбції шлаком (рис. 1). При цьому ефективність процесу і величина адсорбції а зростають (див. табл. 2). При початковому значенні $\mathrm{pH}=6,7$ практично відсутня іонізація як молекул аніліну, так і кислотних груп поверхні шлаку. Розрахована частка неіонізованих молекул (1-a) [1] аніліну (органічної основи з $K_{\mathrm{b}}=$ $\left.3,82 \cdot 10^{-10}[7]\right)$ :

$$
(1-\mathrm{\alpha})=\frac{1}{1+K_{b}\left[\mathrm{H}^{+}\right] \cdot 10^{14}}=\frac{1}{1+3,82 \cdot 10^{-10} \cdot 10^{-6,7} \cdot 10^{14}}=0,9924 .
$$

Таким чином, 99,24 \% молекул аніліну перебувають в неіонізованій формі. Сорбція неіонізованих молекул аніліну відбувається в результаті протонування молекули і утворення іонної пари за схемою:

$$
\mathrm{RCOOH}+\mathrm{C}_{6} \mathrm{H}_{5} \mathrm{NH}_{2} \leftrightarrow \mathrm{RCOO}-\left[\mathrm{C}_{6} \mathrm{H}_{5} \mathrm{NH}_{3}\right]^{+}
$$

без витіснення іонів водню в розчин [1]. Посилення адсорбції за рахунок додаткової взаємодії поверхневих функціональних груп з неіонізованими молекулами слабких електролітів має важливе практичне значення при глибокому очищенні вод. 


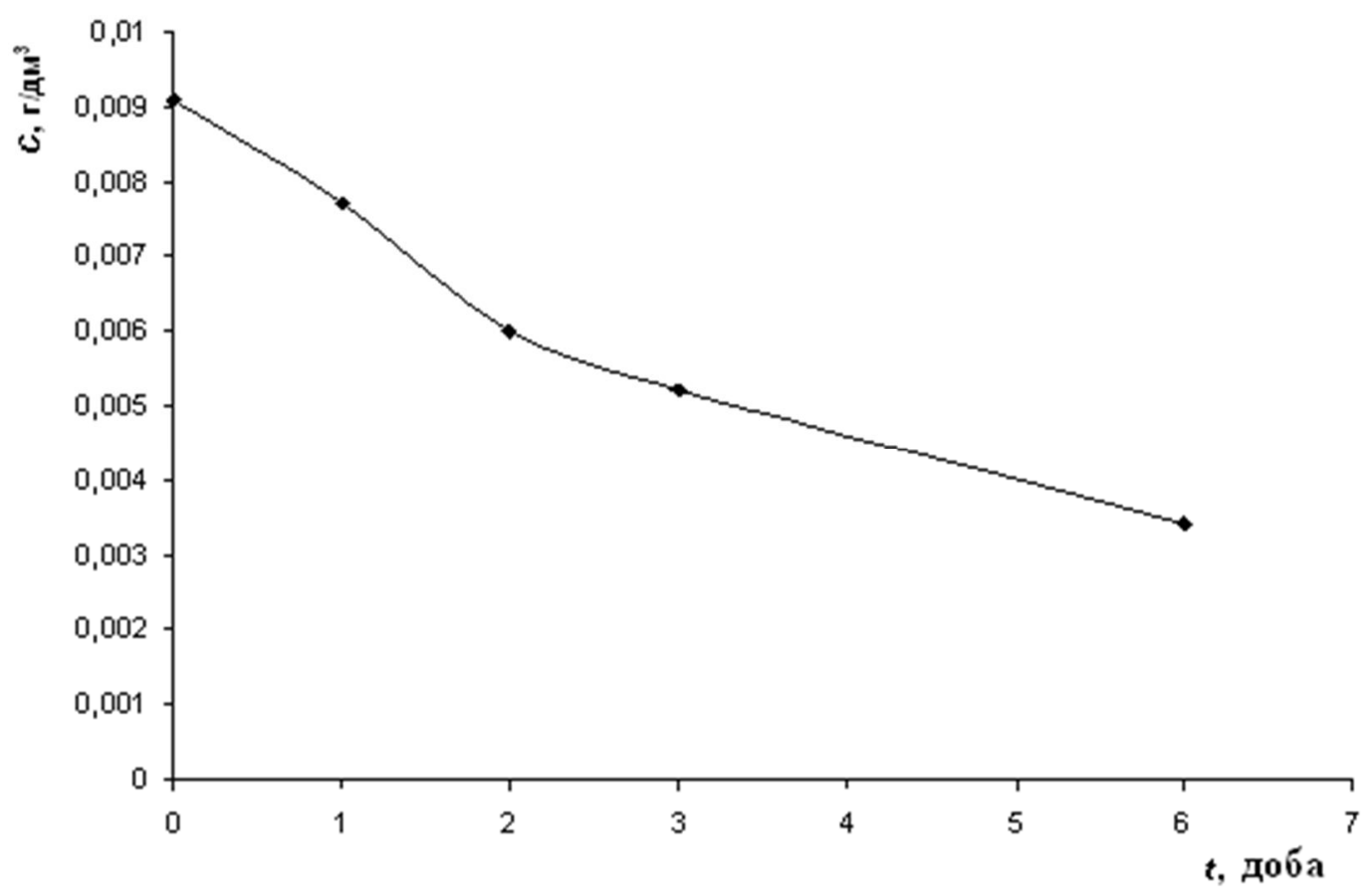

Рис. 1. Зменшення концентрації аніліну в розчині при адсорбції шлаком ПФНК

Табл. 2. Змінення показників адсорбції аніліну шлаком ПФНК в часі (статичний режим адсорбції)

\begin{tabular}{|c|c|c|c|c|}
\hline Час видержки, діб & $\begin{array}{c}\text { рН розчину } \\
\text { наприкінці } \\
\text { адсорбції }\end{array}$ & $C_{\text {анілін, мг/дм }}$ & $\begin{array}{c}\text { Величина } \\
\text { адсорбції } \\
a, \text { мг/г }\end{array}$ & $\begin{array}{c}\text { Ефективність } \\
\text { вилучення } \\
\text { аніліну, \% }\end{array}$ \\
\hline 0 & 6,7 & 9,1 & - & - \\
\hline 1 & 5,8 & 7,7 & 0,028 & 15,4 \\
\hline 2 & 4,6 & 6,02 & 0,062 & 33,8 \\
\hline 3 & - & 5,2 & 0,078 & 42,9 \\
\hline 6 & 6,4 & 3,4 & 0,114 & 62,6 \\
\hline
\end{tabular}

Подібний механізм адсорбції можливий і для n-нітроаніліну. В роботах $[1,8]$ показана незалежність величини адсорбції ряду ароматичних сполук активованим вугіллям від рН розчину, що автори пов'язали з переважною адсорбцією неіонізованих і менш гідратованих молекул. Таким чином, збільшення ефективності адсорбції слабких ароматичних електролітів на шлакових частинках пояснюється зменшенням здатності електролітів до дисоціації, а саме [7]:

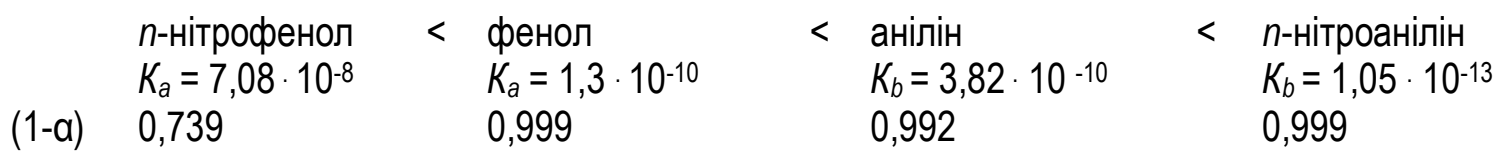

Відхилення в ряду по величинам констант дисоціації Ка для фенолу і $n$-нітрофенолу можна пояснити більш сильною дисоціацією $n$-нітрофенолу і утворенням негативно заряджених частинок $\mathrm{C}_{6} \mathrm{H}_{5} \mathrm{O}^{-}$, електростатична складова адсорбції яких зменшується при відштовхуванні від негативно зарядженої поверхні.

Цікавим $є$ вивчення впливу кислотності розчину на адсорбцію слабких ароматичних електролітів шлаком ПФНК. Згідно з результатами таблиці 3 видно, що зміщення $\mathrm{pH}$ як у кислу, так і в лужну область зменшує адсорбцію $n$-нітроаніліну (див. табл. 3). Частка неіонізованих молекул велика в кожному випадку: 99,24 \% (pH = 3); 99,99\% (pH = 6,7); $\approx 100 \%(\mathrm{pH}=10)$. 
Табл. 3. Вплив кислотності розчину на адсорбцію п-нітроаніліну шлаком ПФНК в статичному режимі протягом 3 діб

\begin{tabular}{|c|c|c|}
\hline \multirow{2}{*}{ pH розчину } & \multicolumn{2}{|c|}{ Концентрація $n$-нітроаніліну, мг/дм ${ }^{3}$} \\
\cline { 2 - 3 } & початкова & кінцева \\
\hline 3,95 & 3,47 & 3,10 \\
\hline 6,7 & 4,51 & 2,44 \\
\hline 10,0 & 3,75 & 3,42 \\
\hline
\end{tabular}

Звідси випливає, що ступінь іонізації п-нітроаніліну як слабкого електроліту і поява позитивного заряду на його молекулі в кислих середовищах не визначає величину адсорбції. У протилежному випадку в кислому середовищі спостерігалося б збільшення адсорбції за рахунок електростатичної взаємодії молекул з негативно зарядженою поверхнею шлаку. Пригнічення адсорбції $n$-нітроаніліну, ймовірно, викликане впливом кислотності розчину на властивості поверхні шлаку. У кислої області пригнічується дисоціація силанольних груп, і зменшується негативний потенціал поверхні. У лужної області відбувається руйнування гелеподібного шару силікатної кислоти, що грає важливу роль в протіканні адсорбції.

Ізотерми адсорбції. Ізотерма адсорбції n-нітроаніліну (рис. 2), отримана в статичному режимі, свідчить про позитивну величину адсорбції в широкому інтервалі рівноважних концентрацій сорбату $C_{p}$. Оптимальним умовам адсорбції відповідає $C_{p}=2,44$ мг / л або співвідношення «сорбат (мг): сорбент (г)» = 0,24: 1. Наявність максимуму на ізотермі адсорбції пов'язано з диполь-дипольним відштовхуванням молекул в адсорбційному шарі, однакова орієнтація яких пов'язана з дисперсійною взаємодією вуглецевого скелета з атомами поверхні.

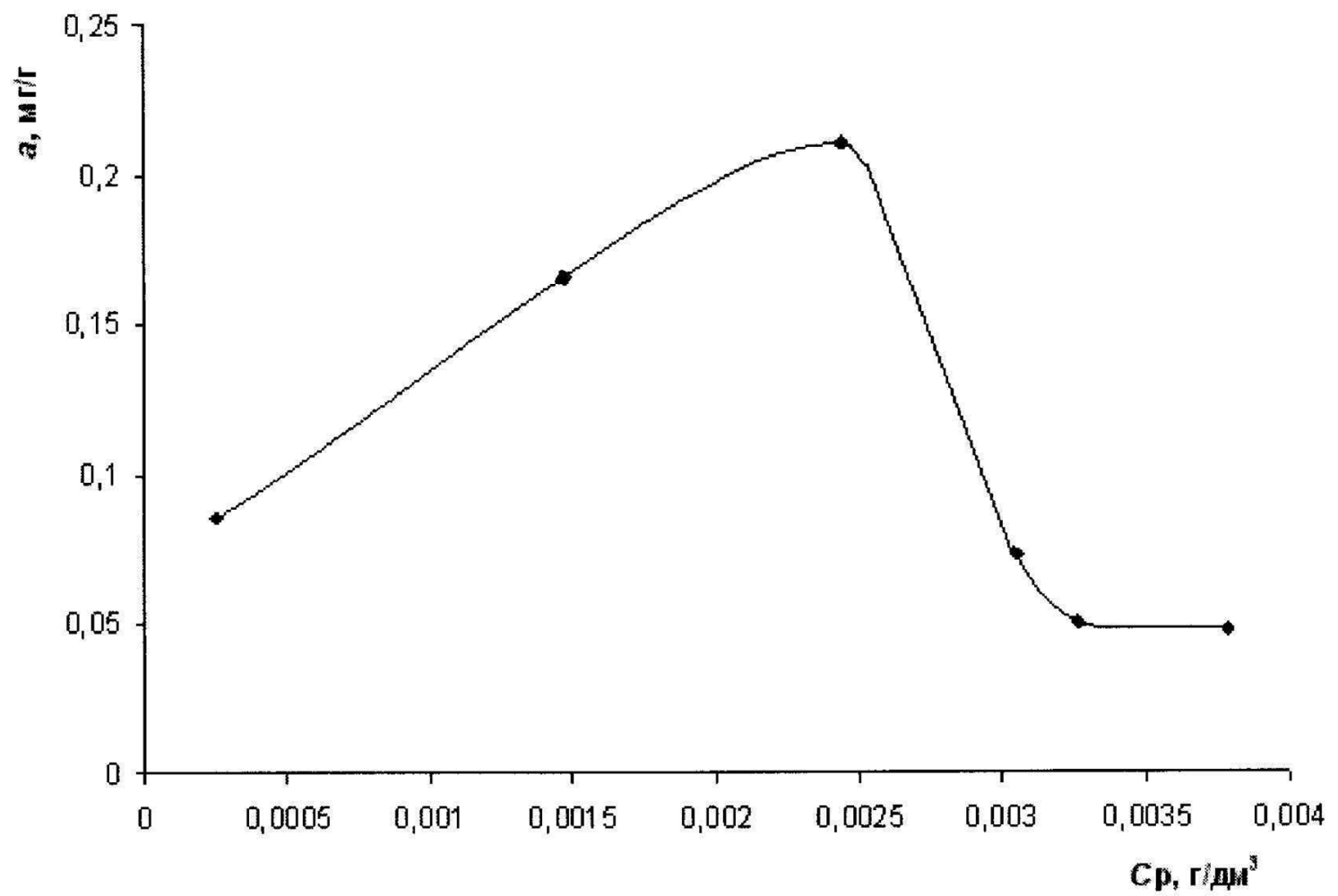

Рис. 2. Ізотерма адсорбції n-нітроаніліну шлаком ПФНК (статичний режим)

Якщо за величину граничної питомої адсорбції $a_{\infty}$ прийняти значення, відповідне максимуму ізотерми адсорбції, то можливо розрахувати ефективну питому поверхню адсорбенту $S_{a}[1]$ : 


$$
S_{\mathrm{a}}=\frac{V_{\mathrm{a}}}{h}=\frac{a_{\infty} \cdot V_{\mathrm{M}}}{h}=\frac{a_{\infty} \cdot M}{h \cdot \rho}=\frac{1,52 \cdot 10^{-6} \cdot 138}{1,424 \cdot 0,37 \cdot 10^{-7}}=0,4 \mathrm{M}^{2} / \mathrm{r},
$$

де: $V_{M}$ - молярний об'єм п-нітроаніліну; $M$ - молярна маса $n$-нітроаніліну 138 г/моль; $\rho$ - щільність $n$ -

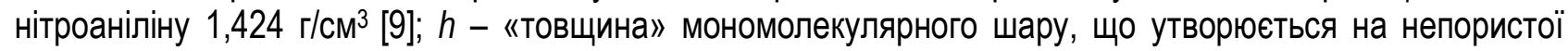
поверхні, рівна для похідних бензолу товщині бензольного кільця 0,37 нм [1].

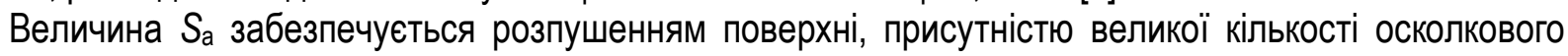
матеріалу, але не пористістю. Пористість шлаку становить $47 \%$, проте більшість пор замкнуті, що характерно для матеріалів, підданих високотемпературній обробці. Відкрита пористість, визначена за різницею об'ємів одиниці маси адсорбенту і істинним об'ємом твердого матеріалу, становить 0,0303 см³/г або 3,03 \%. Тому адсорбція ароматичних сполук протікає не в порах, а на відкритій поверхні шлаку, подібне явище виявлено для адсорбентів різної природи [1].

\section{IV Обговорення}

Висхідної ділянці ізотерми адсорбції відповідає лінійна ізотерма Фрейндліха $\operatorname{lga}=1 / n \lg C_{p}+\lg K$ i ізотерма в координатах $\frac{1}{A}-\frac{1}{C}$, згідно з якими отримані рівняння Фрейндліха і Ленгмюра. Вид рівняння Фрейндліха наступний:

$$
a=8,91 C_{p}^{0,39}
$$

де константа $K=8,91$ моль/дм³.

Рівняння Ленгмюра:

$$
A=A_{\text {гран. }} \frac{K C}{K C+1}=1,8 \cdot 10^{-3} \frac{2,8 \cdot 10^{5} C}{2,8 \cdot 10^{5} C+1}, \text { ммоль/г. }
$$

Велика величина константи адсорбції $K=2,8 \cdot 10^{5} \mathrm{дm}^{3} /$ моль визначалася видом ізотерми адсорбції, ії круто висхідною гілкою. Зміна ізобарно-ізотермічного потенціалу при адсорбції $n$-нітроаніліну шлаком ПФНК дорівнює

$$
\Delta G=-2,3 R 298 \lg K=-3,1 \cdot 10^{4} \text { Дж/моль. }
$$

Високі значення $K$ і величини $-\Delta G=31$ кДж/моль свідчать про ефективність протікання адсорбції n-нітроаніліну на шлаковому адсорбенті. Адсорбція ароматичних сполук протікає як за рахунок взаємодії з поверхневими функціональними групами, так і в результаті дисперсійної взаємодії, тобто $є$ результатом двох рівноваг.

Адсорбовані ароматичні сполуки мають досить великі постійні дипольні моменти $\mu$ [10]: $\mu_{\text {аніліну }}=\mu_{\text {фенолу }}=1,53 ; \mu_{n \text {-нітрофенолу }}=5,01 ; \mu_{n \text {-нітроаніліну }}=6,32$. В даному випадку додатково проявляється їх індукційна електростатична взаємодія з поверхнею адсорбенту. Автори робіт $[11,12]$ показали, що на неполярної вуглецевої поверхні внесок індукційної взаємодії в загальну енергію адсорбції складає всього $10 \%$. Прогнозується, що при досить високій полярності сполук шлакового адсорбенту частка подібної взаємодії буде вище.

\section{V Висновки}

Вивчено особливості визначення кількісних характеристик адсорбції n-нітрофенолу, фенолу, аніліну і $n$-нітроаніліну металургійним шлаком на основі мінералу діопсиду: величину адсорбції, ефективність вилучення сорбатів з рідкої фази, масове співвідношення «сорбент : сорбат», ефективну питому поверхню адсорбенту. Процес адсорбції описаний за допомогою рівнянь Фрейндліха і Ленгмюра.

Отримані експериментальні дані свідчать про те, що основними типами взаємодії «ароматичний вуглеводень - шлаковий адсорбент» є: дисперсійна взаємодія між вуглецевим скелетом молекул сорбатів і атомами адсорбенту; міжмолекулярний водневий зв'язок між функціональними групами органічних молекул і поверхнею адсорбенту; водневий зв'язок між т-електронами бензольного кільця і 
силанольними групами поверхні адсорбенту; утворення іонних пар між функціональними групами поверхні і протонованими функціональними групами недісоційованих молекул сорбатів; електростатична індукційна і орієнтаційна взаємодія при дисоціації фуннкціональних груп поверхні адсорбенту і молекул сорбатів.

Таким чином, правильний вибір партнерів для реалізації різних видів міжмолекулярних взаємодій при адсорбції дозволить вирішити практичні завдання адсорбційного очищення стічних вод, серед яких локальне очищення стічних вод, що утворюються при певних технологічних операціях.

\section{Бібліографрічні посилання}

[1] Когановский А. М., Клименко Н. А., Когановский А. М., Левченко Т. М., Рода И. Г. Адсорбция органических веществ из воды. Л. : Химия, 1990. 256 с.

[2] Грайворонская И., Хоботова Э., Даценко В., Марченко И., Медникова В., Бородкина А. Повышение эфрективности адсорбции - повышение экологической безопасности производственных процессов / Вісник Харківського національного університету ім. В.Н. Каразіна. Харків, 2011. № 944. Вип. 6. С. 98-103.

[3] Хоботова Э. Б., Грайворонская И. В., Даценко В. В., Баумер В. Н. Исследование сорбционных свойств шлаков ферроникелевого производства / Экология и промышленность. 2009. № 4. С. 68-72.

[4] Грайворонская И. В. Выявление сорбционных свойств ферросплавных шлаков в зависимости от их структуры и состава / Экология и промышленность. 2010. № 3. С. 46-52.

[5] Хоботова Э. Б., Грайворонская И. В. Обеспечение экологической безопасности при использовании металлургических шлаков в качестве сорбентов в технологиях очистки вод: монография. Харьков : ХНАДУ, 2013. 204 с.

[6] Киселев А. В. Межмолекулярные взаимодействия в адсорбции и хроматографии. М. : Высшая школа, 1986. 360 с.

[7] Несмеянов А. Н., Несмеянов Н. А. Начала органической химии. Книга ІІ. М. : Химия, 1974. 744 с.

[8] Ровинская Т. М. Оптимальные условия адсорбции ароматических соединений из промышленных сточных вод / В кн.: Исследования в области промышленного применения сорбентов. М. : Изд-во АН СССР, 1961. С. 121-126.

[9] Химическая энциклопедия. Т. 3. М.: Научное изд-во «Большая Российская энциклопедия», 1992. 639 с.

[10] Осипов О. А., Минкин В. И., Гарновский А. Д. Справочник по дипольным моментам. М. : Высшая школа, 1971. 416 с.

[11] Авгуль Н. Н., Киселев А. В., Пошкус Д. П. Адсорбция газов и паров на однородных поверхностях. М. : Химия, 1975. $384 \mathrm{c}$.

[12] Margenay H., Kestner N. R. Theory of Intermolecular Forces. London : Pergamon Press, 1971. 400 p.

\section{References}

[1] Koganovskiy, A. M., Klimenko, N. A., Koganovskiy, A. M., Levchenko, T. M., Roda, I. G. (1990). Adsorbtsiya organicheskikh veshchestv iz vody. Leningrad, Khimiya. (in Russian)

[2] Hraivoronska, I., Khobotova, E., Datsenko, V., Marchenko, I., Mednikova, V., Borodkina, A. (2011). Povyshenie effektivnosti adsorbtsii - povyshenie ekologicheskoy bezopasnosti proizvodstvennykh protsessov. Visnik Kharkivs'kogo natsional'nogo universitetu im. V.N. Karazina. Kharkiv, № 944, Iss. 6, 98-103. (in Russian)

[3] Khobotova, E. B., Hraivoronska, I. V., Datsenko, V. V., Baumer, V. N. (2009). Issledovanie sorbtsionnykh svoystv shlakov ferronikelevogo proizvodstva. Ekologiya i promyshlennost', № 4, 68-72. (in Russian)

[4] Hraivoronska, I. V. (2010). Vyyavlenie sorbtsionnykh svoystv ferrosplavnykh shlakov v zavisimosti ot ikh struktury i sostava. Ekologiya i promyshlennost', № 3, 46-52. (in Russian)

[5] Khobotova, E. B., Hraivoronska, I. V. (2013). Obespechenie ekologicheskoy bezopasnosti pri ispol'zovanii metallurgicheskikh shlakov v kachestve sorbentov $v$ tekhnologiyakh ochistki vod: monografiya. Khar'kov, KhNADU. (in Russian)

[6] Kiselev, A. V. (1986). Mezhmolekulyarnye vzaimodeystviya v adsorbtsii i khromatografii. Moscow, Vysshaya shkola. (in Russian)

[7] Nesmeyanov, A. N., Nesmeyanov, N. A. (1974). Nachala organicheskoy khimii. Kniga II. Moscow, Khimiya. (in Russian)

[8] Rovinskaya, T. M. (1961). Optimal'nye usloviya adsorbtsii aromaticheskikh soedineniy iz promyshlennykh stochnykh vod / V kn.: Issledovaniya v oblasti promyshlennogo primeneniya sorbentov. Moscow, Izd-vo AN SSSR, 121-126. (in Russian)

[9] (1992). Khimicheskaya entsiklopediya. T. 3. M.: Nauchnoe izd-vo «Bol'shaya Rossiyskaya entsiklopediya». (in Russian)

[10] Osipov, O. A., Minkin, V. I., Garnovskiy, A. D. (1971). Spravochnik po dipol'nym momentam. Moscow, Vysshaya shkola. (in Russian)

[11] Avgul', N. N., Kiselev, A. V., Poshkus, D. P. (1975). Adsorbtsiya gazov i parov na odnorodnykh poverkhnostyakh. Moscow, Khimiya. (in Russian)

[12] Margenay, H., Kestner, N. R. (1971). Theory of Intermolecular Forces. London, Pergamon Press. 


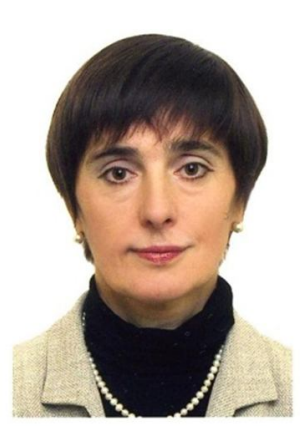

\section{Хоботова Еліна Борисівна,}

доктор хімічних наук, професор, профресор кафедри технології дорожньо-будівельних матеріалів і хімії, Харківський національний автомобільно-дорожній університет,

вул. Ярослава Мудрого, 25, м. Харків, Україна, 61002.

Тел. 0958804419. E-mail: chemistry@khadi.kharkov.ua

\section{Khobotova Elina Borysivna,}

D.Sc. (Chem.), Professor, Professor of The Department of Technology of Road-Construction Materials,

Kharkiv National Automobile and Highway University,

vul. Yaroslava Mudroho, 25, Kharkiv, Ukraine, 61002.

Phone: (095)880-44-19. E-mail: chemistry@khadi.kharkov.ua

ORCID: https://orcid.org/0000-0003-4855-2763

Scopus ID: 6602901694

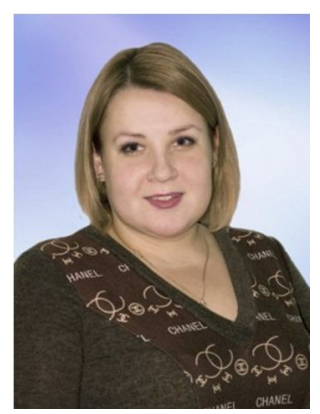

\section{Грайворонська Інна Валеріївна,}

кандидат технічних наук, доцент кафедри метрології та безпеки життєдіяльності,

Харківський національний автомобільно-дорожній університет,

вул. Ярослава Мудрого, 25, м. Харків, Україна, 61002.

Тел. (050)859-64-14. E-mail: inna_gra@ukr.net

\section{Hraivoronska Inna Valeriivna,}

Cand.Sc. (Eng.), Associate Professor of Metrology and Safety of Human Vital Activities Department,

Kharkiv National Automobile and Highway University,

vul. Yaroslava Mudroho, 25, Kharkiv, Ukraine, 61002.

Phone: (050)859-64-14. E-mail: inna_gra@ukr.net

\section{Citation (APA):}

Khobotova, E., Hraivoronska, I. (2018). Study features of quantitative characteristics of organic compounds sorption by metallurgical slag. Engineering and Educational Technologies, 6 (3), 17-24. doi: https://doi.org/10.30929/2307-9770.2018.06.03.02 (in Ukranian)

\section{Цитування (ДСТУ 8302:2015):}

Хоботова Е. Б., Грайворонська І. В. Особливості вивчення кількісних характеристик сорбції органічних сполук металургійним шлаком / Інженерні та освітні технологіï. 2018. Т. 6. № 3. С. 17-24. doi: https://doi.org/10.30929/2307-9770.2018.06.03.02

Обсяг статті: 8 сторінок, 0,920 умовних друк. аркушів. 